Article

\title{
Burkholderia cenocepacia Prophages-Prevalence, Chromosome Location and Major Genes Involved
}

\author{
Bartosz Roszniowski ${ }^{1}$, Siobhán McClean ${ }^{2}$ id and Zuzanna Drulis-Kawa ${ }^{1, *}$ (D) \\ 1 Institute of Genetics and Microbiology, University of Wroclaw, 51-148 Wroclaw, Poland; \\ bartosz.roszniowski@gmail.com \\ 2 School of Biomolecular and Biomedical Science, University College Dublin, Belfield, Dublin 4, Ireland; \\ siobhan.mcclean@ucd.ie \\ * Correspondence: zuzanna.drulis-kawa@uwr.edu.pl; Tel.: +48-71-375-62-90
}

Received: 12 April 2018; Accepted: 29 May 2018; Published: 31 May 2018

\begin{abstract}
Burkholderia cenocepacia, is a Gram-negative opportunistic pathogen that belongs to Burkholderia cepacia complex (BCC) group. BCC representatives carry various pathogenicity factors and can infect humans and plants. Phages as bacterial viruses play a significant role in biodiversity and ecological balance in the environment. Specifically, horizontal gene transfer (HGT) and lysogenic conversion (temperate phages) influence microbial diversification and fitness. In this study, we describe the prevalence and gene content of prophages in 16 fully sequenced B. cenocepacia genomes stored in NCBI database. The analysis was conducted in silico by manual and automatic approaches. Sixty-three potential prophage regions were found and classified as intact, incomplete, questionable, and artifacts. The regions were investigated for the presence of known virulence factors, resulting in the location of sixteen potential pathogenicity mechanisms, including toxin-antitoxin systems (TA), Major Facilitator Superfamily (MFS) transporters and responsible for drug resistance. Investigation of the region's closest neighborhood highlighted three groups of genes with the highest occurrence-tRNA-Arg, dehydrogenase family proteins, and ABC transporter substrate-binding proteins. Searches for antiphage systems such as BacteRiophage EXclusion (BREX) and Clustered Regularly Interspaced Short Palindromic Repeats (CRISPR) in the analyzed strains suggested 10 sequence sets of CRISPR elements. Our results suggest that intact B. cenocepacia prophages may provide an evolutionary advantage to the bacterium, while domesticated prophages may help to maintain important genes.
\end{abstract}

Keywords: Burkholderia cenocepacia; prophages; prevalence; in silico analyses

\section{Introduction}

The Burkholderia genus, named after its discoverer, Walter Burkholder [1,2] includes Gram-negative bacteria that cause plant disease (e.g., sour skin rot disease), but paradoxically they also act as natural pest antagonists by promoting plant growth [3,4]. There are also reports that Burkholderia lipopolysaccharide (LPS) is a factor which induces plant defensive capacity [5].

Burkholderia cenocepacia is a multidrug resistant, opportunistic pathogen. B. cenocepacia belongs to the Burkholderia cepacia complex (BCC), a group of 21 species of opportunistic pathogens that colonizes patients with cystic fibrosis (CF) and chronic granulomatous disease (CGD) [6]. Although, BCC representatives are responsible for only $3.5 \%$ of infections in $\mathrm{CF}$ patients, the fatality rate is higher than in the more commonly acquired Pseudomonas aeruginosa infection [7].

Following colonization of the host by BCC, the likelihood of complete eradication is very low. The course of infection differs depending on the CF status and may range from asymptomatic to severe inflammation of the lower respiratory tract, leading to lung function decline and ultimately to the 
patient's death. Twenty percent of infected individuals develop "cepacia syndrome", characterized by a high fever, pneumonia and severe bacteraemia [8]. Treatment is hindered by the pathogen's inherent antimicrobial drug resistance, including insensitivity to fluoroquinolones, aminoglycosides and $\beta$-lactams [9]. Further, BCC bacteria are highly resistant to antimicrobial peptides and even has the ability to use penicillin $\mathrm{G}$ as a carbon source. BCC may form biofilms, further enhancing their resistance to antibiotics $[10,11]$.

The mechanisms of BCC pathogenicity are multifactorial and complex. Because of that, finding solid strategies to combat infections caused by these bacteria is very challenging [12]. There are several known virulence mechanisms that have been reported to date: (i) invasion of epithelial cells and access to the bloodstream; (ii) structures responsible for adhesion (pili, flagella); (iii) LPS specific to Gram-negative bacteria; (iv) secretion systems (types I-IV); (v) biofilm formation; (vi) toxin-antitoxin (TA) systems; (vii) quorum sensing (QS) systems regulating expression of multiple virulence factors (e.g., toxins, proteases, lipases); and (viii) drug-resistance [13-20]. Of all the listed BCC virulence factors, only TA systems were described previously as encoded by prophages [21].

The genetic material of prophages is replicated by bacteria during its division, resulting in mutual benefits for the virus and its host. In addition, prophages can contribute to the enhancement of environment survival of infected cells by transferring genes which allow the exploitation of new nutrient sources and encode specific enzymes and toxins. Further, bacteriophages play a key role in the diversification of bacteria by immunizing their hosts against homologous viruses. All these factors can influence the survival of strains and changes in the composition of populations prevailing in a given environment. The process of gene donation by phages to the hosts is defined as lysogenic conversion [22]. It is suspected that prophages equip bacteria with toxins and enzymes, allowing their hosts to invade higher organisms and avoid the immune response and ultimately leading to increased pathogenicity of the bacteria [23]. Lysogenic conversion also plays an important role in transmitting antibiotic resistance. Such phenomenon was described for Streptococcus-specific phages transferring drug-resistance to chloramphenicol, macrolides, lincomycin and clindamycin [24].

Prophages can comprise a significant component of bacterial genetic material. In Escherichia coli O157 and Streptococcus pyogenes M3 MGAS 315, prophages account for up to $12 \%$ of the chromosomal DNA. In bacteria with smaller genomes, such as Borrelia burgdorferi, prophages exist as linear or circular episomes (plasmids). B. burgdorferi B31 is a particular example of such pseudolysogeny, as the episomal temperate phages may make up to $20 \%$ of its total genome [25]. It was assumed that this is caused by the evolutionary pressure of bacteria, which manifests in the removal of unessential DNA from its chromosome, maintaining the genome size at a particularly reduced level [26]. Bacteria hosting certain prophage may conduct a bacteriophage "domestication" process. This phenomenon is based on the modification of genetic material present in the cell, including nonsynonymous substitutions of nucleotides or deletions of whole genes (or regions). This leads to a partial or total disorder of the phage life cycle inhibiting prophage induction and lytic form of propagation. Overall, "domestication" results in the progressive removal of prophage genetic material, leaving only those sequences which are essential for bacteria. In most cases, these entities are referred to as cryptic phages. Once the phage DNA is just limited to individual genes or incomplete regions, it is referred to as a bacteriophage artifact [25]. The remaining phage regions may undergo further recombination with other prophages, plasmids and gene clusters which were already present within bacterial genome $[27,28]$.

To date, there are 39 sequenced BCC phages in the NCBI database and two additional phage, phiK96243 and $\phi H 111-1$, not in the database (Table S1). Phage phiK96243 and $\phi H 111-1$ were described but their sequences were not submitted to any database as standalone sequence [21,29]. Twenty-three phages possess either integrase or recombinase (suggesting their temperate lifestyle) however only fourteen were labeled as temperate in the literature. Six of remaining phages are lytic, while 19 are unclassified. The taxonomical division places 19 phages in Myoviridae, 10 in Podoviridae and nine in Siphoviridae. The phiK96243 has not yet been classified. 
In this study we analyzed 16 B. cenocepacia strains with fully sequenced genomes stored in the NCBI database. The main goals were to search for the presence and prevalence of prophages and their gene composition. Further, phage accumulation in particular chromosomes, location site (integration point), and closest neighborhood (flanking sequences) were also investigated. The occurrence of known virulence factors of $B$. cenocepacia was examined to determine if they were any of phage origin. All identified prophages were compared phylogenetically, to establish their taxonomic relationship. The analysis was done by in silico methods, based on two different approaches, one fully automatic and one manual approach to highlight the advantages and disadvantages of both techniques.

\section{Materials and Methods}

\subsection{PHASTER Automated Annotation}

Genomes of B. cenocepacia used for the analysis were obtained from the NCBI database (http:/ / www. ncbi.nlm.nih.gov /) and were chosen based on completeness of sequence. Other incomplete sequences were omitted (as of 31.05.2017), leaving 16 bacterial genomes for further analysis (Table 1). Most B. cenocepacia strains have three chromosomes and each one was analyzed separately [30].

Table 1. B. cenocepacia strains chosen for analysis.

\begin{tabular}{|c|c|c|c|c|c|}
\hline No. & Strain & Origin & Chromosome & $\mathbf{A} / \mathbf{N}$ & Genome Size (bp) \\
\hline \multirow{3}{*}{1} & \multirow{3}{*}{$\begin{array}{l}\text { B. cenocepacia } \\
\text { J2315 }\end{array}$} & \multirow{3}{*}{$\mathrm{CF}$} & 1 & NC_011000.1 & $3,870,082$ \\
\hline & & & 2 & NC_011001.1 & $3,217,062$ \\
\hline & & & 3 & NC_011002.1 & 875,977 \\
\hline \multirow{3}{*}{2} & \multirow{3}{*}{$\begin{array}{c}\text { B. cenocepacia } \\
\text { H111 }\end{array}$} & \multirow{3}{*}{$\mathrm{CF}$} & 1 & NZ_HG938370.1 & $3,572,953$ \\
\hline & & & 2 & NZ_HG938371.1 & $3,102,677$ \\
\hline & & & 3 & NZ_HG938372.1 & $1,039,263$ \\
\hline \multirow{3}{*}{3} & \multirow{3}{*}{$\begin{array}{l}\text { B. cenocepacia } \\
\text { DWS 37E-2 }\end{array}$} & \multirow{3}{*}{ Soil } & 1 & NZ_CP007781.1 & $3,241,886$ \\
\hline & & & 2 & NZ_CP007780.1 & $2,375,865$ \\
\hline & & & 3 & NZ_CP007779.1 & 994,670 \\
\hline \multirow[b]{2}{*}{4} & B. cenocepacia & \multirow[b]{2}{*}{ Soil } & 1 & СР013397.1 & $3,461,321$ \\
\hline & FL-5-3-30-S1-D7 & & 2 & СР013396.1 & $2,869,430$ \\
\hline \multirow[b]{2}{*}{5} & \multirow{2}{*}{$\begin{array}{l}\text { B. cenocepacia } \\
\quad 895\end{array}$} & \multirow{2}{*}{ Sepsis (neonatal)/Cord blood } & 1 & NZ_CP015036.1 & $7,459,003$ \\
\hline & & & 2 & NZ_CP015037.1 & $1,072,666$ \\
\hline \multirow{3}{*}{6} & \multirow{3}{*}{$\begin{array}{l}\text { B. cenocepacia } \\
\text { ST32 }\end{array}$} & \multirow{3}{*}{$\mathrm{CF}$} & 1 & NZ_CP011917.1 & $3,822,749$ \\
\hline & & & 2 & NZ_CP011918.1 & $3,086,109$ \\
\hline & & & 3 & NZ_CP011919.1 & 989,585 \\
\hline \multirow{3}{*}{7} & \multirow{3}{*}{$\begin{array}{l}\text { B. сепосерасіа } \\
842\end{array}$} & \multirow{3}{*}{ Nasal inflammation/non-CF } & 1 & NZ_CP015033.1 & $3,526,250$ \\
\hline & & & 2 & NZ_CP015034.1 & $3,107,451$ \\
\hline & & & 3 & NZ_CP015035.1 & $1,271,875$ \\
\hline \multirow{3}{*}{8} & \multirow{3}{*}{$\begin{array}{l}\text { B. сепосерасіа } \\
\text { MSMB384WGS }\end{array}$} & \multirow{3}{*}{ Water } & 1 & NZ_CP013450.1 & $3,588,848$ \\
\hline & & & 2 & NZ_CP013452.1 & $3,069,864$ \\
\hline & & & 3 & NZ_CP013451.1 & $1,121,886$ \\
\hline \multirow{3}{*}{9} & \multirow{3}{*}{$\begin{array}{l}\text { B. сепосерасіа } \\
\text { HI } 2424\end{array}$} & \multirow{3}{*}{ Soil } & 1 & NC_008542.1 & $3,483,902$ \\
\hline & & & 2 & NC_008543.1 & $2,998,664$ \\
\hline & & & 3 & NC_008544.1 & $1,055,417$ \\
\hline \multirow{3}{*}{10} & & & 1 & NZ_CP017238.1 & $3,511,146$ \\
\hline & B. сепосерасіа & Plant root & 2 & NZ_CP017239.1 & $3,097,552$ \\
\hline & & & 3 & NZ_CP017240.1 & $1,056,196$ \\
\hline & & & 1 & NC_008060.1 & $3,294,563$ \\
\hline 11 & B. сепосерасіа & $\mathrm{CF}$ & 2 & NC_008061.1 & $2,788,459$ \\
\hline & & & 3 & NC_008062.1 & $1,196,094$ \\
\hline & & & 1 & NC_010508.1 & $3,532,883$ \\
\hline 12 & B. сепосерасіа & Soil & 2 & NC_010515.1 & $3,213,911$ \\
\hline & & & 3 & NC_010512.1 & $1,224,595$ \\
\hline & & & 1 & NZ_CP007783.1 & $3,668,832$ \\
\hline 13 & B. сепосерасіа & Aerosol sample & 2 & NZ_CP007784.1 & $3,209,624$ \\
\hline & & & 3 & NZ_CP007782.1 & $1,166,794$ \\
\hline
\end{tabular}


Table 1. Cont.

\begin{tabular}{cccccc}
\hline No. & Strain & Origin & Chromosome & A/N & Genome Size (bp) \\
\hline \multirow{2}{*}{14} & B. cenocepacia & CF & 1 & NZ_CP019668.1 & $7,499,459$ \\
& VC7848 & & & & \\
\hline \multirow{2}{*}{15} & B. cenocepacia & \multirow{2}{*}{ CF } & NZ_CP019674.1 & $3,668,000$ \\
& VC12308 & & 2 & NZ_CP019672.1 & $2,984,720$ \\
& & \multirow{2}{*}{ CF } & 1 & NZ_CP019673.1 & 964,521 \\
\hline \multirow{2}{*}{16} & B. cenocepacia & & NZ_CP019670.1 & $6,339,862$ \\
& VC12802 & CF-sample collected from cystic fibrosis patient.
\end{tabular}

The prophages were located using PHASTER [31]. PHASTER scores potential phage regions using one of three methods, all of which are based on comparisons with the NCBI complete virus genome table (direct link to the table in citation) [32]. Based on the score, the region was assigned to one of three categories: intact (score higher than 90), questionable (score between 70 and 90) and incomplete (score below 70). The first method of scoring regions utilizes global comparison of the region with each of phages in the NCBI table as follows: if there is $100 \%$ or more conformity between total number of the CDS in both sources, the region score is set to 150. If the first method fails, the second or third one is used sequentially. The second evaluation is divided for three steps: (i) designation of the most probable potential phage (in the same manner as the first method, although with a minimum conformity level of $50 \%$ ); (ii) the percentage comparison of the amount of proteins in the region and most probable potential phage, checked and multiplied by 100 (giving a partial score); (iii) the percentage comparison of the region and major potential phage length is checked and multiplied by 50 and added to the partial score from the step "ii", giving the final score. The last method relies on the keywords contained in the names of phage specific proteins (also called "cornerstones") present within particular region. PHASTER searches for words such as: "capsid", "coat", "fiber", "head", "integrase", "lysin", "plate", "tail", "portal", "terminase", "transposase", etc. Each of those hits grants 10 points for particular region. Additionally, up to 20 points can be awarded, if the region size is greater than $30 \mathrm{~kb}$ and there are at least 40 proteins in it.

PHASTER runs the second and third method in parallel, leaving the higher score as the final one for particular region $[31,33]$.

\subsection{Manual Annotation}

The annotation of prophage genomes was performed twice-once via a PHASTER automated annotation during the prophage region search and secondly by a manual search. During the manual annotation the open reading frames were delimited with Artemis (open reading frame (ORF) size equal or higher than $75 \mathrm{nt}$ ) and confirmed with GenMarkS [34,35]. All sequences of identified open reading frames were compared with the NCBI database using BLASTN and BLASTP and annotated accordingly $[36,37]$. In certain cases where BLAST results were questionable or were difficult to assess (hypothetical proteins), HMMER software was used to verify the protein structure and domains [38].

Manual annotation was enriched by additional verification of 10 open reading frames lying upstream and downstream of regions found by PHASTER, to confirm or refute their involvement in a potential prophage genome. The regions were searched for the presence of regulatory sequences during the manual annotation. The transfer RNA's localization was conducted using Aragorn and confirmed by tRNAscan-SE [39,40]. Potential Rho-independent terminators were found using ARNold and curated manually [41]. The search for putative promoters was done by extraction of 100-nt sequences lying upstream of the predicted ORFs using STORM and their analysis by MEME [42,43]. MEME identified repetitive motifs which were investigated manually. Once identified, the sequence and localization of any regulatory sequences were marked in region characteristics cards (Supplementary Materials). Both annotation methods were compared in the tables (Tables S2-S17). Each table includes the manual 
and automatic annotation of one region, tabulating the localization of each ORF, the virus to which it holds homology as well as its accession numbers.

\subsection{Phylogeny Analysis}

Phylogeny reconstruction trees based on of the maximum likelihood method were prepared using Mega7. This software was set to use Jones-Taylor-Thornton (JTT) matrix-based model, while Neighbor-Join and BioNJ algorithms were applied to create an initial tree for heuristic search [44,45].

The graphical mapping of genomes was based on the PHASTER output data and confirmed by EasyFig 2.1 [46]. The location of regions in the host genomes was prepared with Circos (v. 0.67, Canada's Michael Smith Genome Sciences Centre) [47].

\section{Results}

In the 16 B. cenocepacia genomes analyzed, sixty-three potential prophage sequences were detected (Table 2). Each region name was created based on its bacterial host with the addition of the chromosome number in which the prophage lay. The location of prophages and their initial completeness analysis were performed automatically with PHASTER to make three different categories: intact (marked in table as green), incomplete (marked red) and questionable (marked blue) (Table 2). Only intact regions were further annotated manually and compared in terms of taxonomy to known phages (based on NCBI database). The visualization of their genome map, investigation of regional neighborhood genes and phylogenetic comparisons were also done. The latter two analyses were also used for incomplete regions.

Table 2. Presence of prophages in Burkholderia cenocepacia genomes stored in the NCBI database. Regions types were marked with colors: intact (green), questionable (blue) incomplete (red) and artifact region (yellow). Table containing more detailed data can be found in Supplementary data (Table S18).

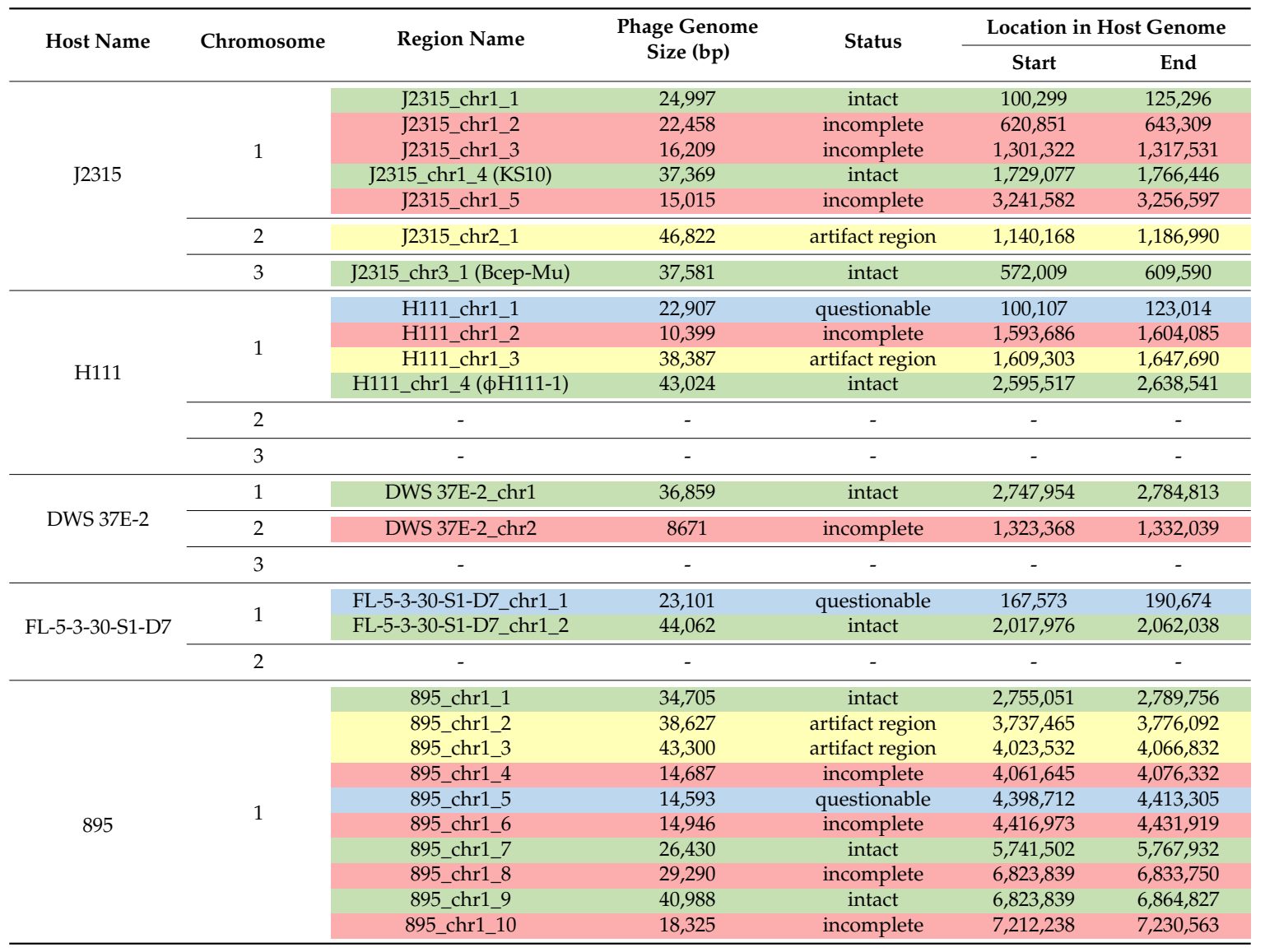


Table 2. Cont.

\begin{tabular}{|c|c|c|c|c|c|c|}
\hline \multirow{3}{*}{ Host Name } & \multirow{2}{*}{ Chromosome } & \multirow{2}{*}{ Region Name } & \multirow{2}{*}{$\begin{array}{l}\text { Phage Genome } \\
\text { Size (bp) }\end{array}$} & \multirow{2}{*}{ Status } & \multicolumn{2}{|c|}{ Location in Host Genome } \\
\hline & & & & & Start & End \\
\hline & 2 & 895_chr2_1 & 37,652 & intact & 826,395 & 864,047 \\
\hline \multirow{3}{*}{ ST32 } & 1 & ST32_chr1 & 23,895 & questionable & $2,869,763$ & $2,893,658$ \\
\hline & 2 & ST32_chr2 & 10,694 & incomplete & $2,980,754$ & $2,991,448$ \\
\hline & 3 & ST32_chr3 & 20,608 & incomplete & 850,166 & 870,774 \\
\hline \multirow{3}{*}{842} & 1 & 842_chr1_1 & 10,037 & incomplete & 57,007 & 67,044 \\
\hline & 2 & $\begin{array}{l}\text { 842_chr2_1 } \\
\text { 842_chr2_2 } \\
\text { 842_chr2_3 } \\
\text { 842_chr2_4 }\end{array}$ & $\begin{array}{l}8621 \\
9739 \\
7465 \\
7448 \\
\end{array}$ & $\begin{array}{l}\text { incomplete } \\
\text { incomplete } \\
\text { incomplete } \\
\text { incomplete }\end{array}$ & $\begin{array}{c}6423 \\
791,624 \\
1,038,705 \\
2,281,847 \\
\end{array}$ & $\begin{array}{c}15,044 \\
801,363 \\
1,046,170 \\
2,289,295 \\
\end{array}$ \\
\hline & 3 & - & - & - & - & - \\
\hline \multirow{3}{*}{ MSMB384WGS } & 1 & $\begin{array}{l}\text { MSMB384WGS_chr1_1 } \\
\text { MSMB384WGS_chr1_2 }\end{array}$ & $\begin{array}{l}24,156 \\
48,964\end{array}$ & $\begin{array}{l}\text { questionable } \\
\text { artifact region }\end{array}$ & $\begin{array}{c}172,483 \\
1,394,910\end{array}$ & $\begin{array}{c}195,500 \\
1,443,874\end{array}$ \\
\hline & 2 & $\begin{array}{l}\text { MSMB384WGS_chr2_1 } \\
\text { MSMB384WGS_chr2_2 }\end{array}$ & $\begin{array}{l}8810 \\
7306\end{array}$ & $\begin{array}{l}\text { incomplete } \\
\text { incomplete }\end{array}$ & $\begin{array}{l}1,087,426 \\
2,234,278\end{array}$ & $\begin{array}{l}1,096,236 \\
2,241,584\end{array}$ \\
\hline & 3 & - & - & - & - & - \\
\hline \multirow[t]{3}{*}{ HI2424 } & 1 & $\begin{array}{l}\text { HI2424_chr1_1 } \\
\text { HI2424_chr1_2 } \\
\text { HI2424_chr1_3 } \\
\text { HI2424_chr1_4 }\end{array}$ & $\begin{array}{l}8280 \\
9114 \\
8107 \\
7746 \\
\end{array}$ & $\begin{array}{l}\text { incomplete } \\
\text { incomplete } \\
\text { incomplete } \\
\text { incomplete }\end{array}$ & $\begin{array}{l}1,165,247 \\
1,383,513 \\
1,556,642 \\
2,976,934 \\
\end{array}$ & $\begin{array}{l}1,173,527 \\
1,392,627 \\
1,564,749 \\
2,984,680 \\
\end{array}$ \\
\hline & 2 & HI2424_chr2_1 & 20,628 & questionable & 126,942 & 147,570 \\
\hline & 3 & $\begin{array}{l}\text { HI2424_chr3_1 } \\
\text { HI2424_chr3_2 }\end{array}$ & $\begin{array}{l}8809 \\
8134\end{array}$ & $\begin{array}{l}\text { incomplete } \\
\text { incomplete }\end{array}$ & $\begin{array}{l}421,282 \\
872,989\end{array}$ & $\begin{array}{l}430,091 \\
881,123\end{array}$ \\
\hline \multirow{3}{*}{ CR 318} & 1 & $\begin{array}{l}\text { CR 318_chr1_1 } \\
\text { CR 318_chr1_2 } \\
\text { CR 318_chr1_3 }\end{array}$ & $\begin{array}{l}38,476 \\
16,791 \\
22,450\end{array}$ & $\begin{array}{c}\text { intact } \\
\text { incomplete } \\
\text { questionable }\end{array}$ & $\begin{array}{c}300,609 \\
1,309,949 \\
2,180,663\end{array}$ & $\begin{array}{c}339,084 \\
1,326,739 \\
2,203,112\end{array}$ \\
\hline & 2 & - & - & - & - & - \\
\hline & 3 & $\begin{array}{l}\text { CR 318_chr3_1 } \\
\text { CR 318_chr3_2 }\end{array}$ & $\begin{array}{c}11,919 \\
7542\end{array}$ & $\begin{array}{l}\text { incomplete } \\
\text { incomplete }\end{array}$ & $\begin{array}{l}112734 \\
570,308\end{array}$ & $\begin{array}{r}124652 \\
577,849 \\
\end{array}$ \\
\hline \multirow{3}{*}{ AU 1054} & 1 & AU 1054_chr1_1 & 24,119 & incomplete & $1,172,051$ & $1,196,169$ \\
\hline & 2 & - & - & - & - & - \\
\hline & 3 & - & - & - & - & - \\
\hline \multirow{3}{*}{ MC0-3 } & 1 & $\begin{array}{l}\text { MC0-3_chr1_1 } \\
\text { MC0-3_chr1_2 }\end{array}$ & $\begin{array}{l}38,872 \\
10,797\end{array}$ & $\begin{array}{c}\text { intact } \\
\text { questionable }\end{array}$ & $\begin{array}{c}198,439 \\
1,405,878\end{array}$ & $\begin{array}{c}237,310 \\
1,416,674\end{array}$ \\
\hline & 2 & - & - & - & - & - \\
\hline & 3 & - & - & - & - & - \\
\hline \multirow{3}{*}{ DDS 22E-1 } & 1 & $\begin{array}{l}\text { DDS 22E-1_chr1_1 } \\
\text { DDS 22E-1_chr1_2 }\end{array}$ & $\begin{array}{l}24,368 \\
31,311\end{array}$ & $\begin{array}{l}\text { incomplete } \\
\text { intact }\end{array}$ & $\begin{array}{l}1,606,100 \\
1,625,635\end{array}$ & $\begin{array}{l}1,630,467 \\
1,656,945\end{array}$ \\
\hline & 2 & DDS 22E-1_chr2_1 & 9602 & incomplete & $1,022,571$ & $1,032,172$ \\
\hline & 3 & - & - & - & - & - \\
\hline VC7848 & 1 & $\begin{array}{l}\text { VC7848_chr1_1 } \\
\text { VC7848_chr1_2 }\end{array}$ & $\begin{array}{c}7080 \\
38,294\end{array}$ & $\begin{array}{l}\text { incomplete } \\
\text { intact }\end{array}$ & $\begin{array}{c}983,606 \\
6,353,033\end{array}$ & $\begin{array}{c}990,685 \\
6,391,326\end{array}$ \\
\hline \multirow{3}{*}{ VC12308 } & 1 & VC12308_chr1_1 & 22,704 & intact & 70,339 & 93,042 \\
\hline & 2 & - & - & - & - & - \\
\hline & 3 & VC12308_chr3_1 & 20,452 & incomplete & 73,079 & 93,531 \\
\hline \multirow{2}{*}{ VC12802 } & 1 & VC12802_chr1_1 & 39,072 & questionable & $3,934,787$ & $3,973,858$ \\
\hline & 2 & $\begin{array}{l}\text { VC12802_chr2_1 } \\
\text { VC12802_chr2_2 }\end{array}$ & $\begin{array}{c}11,921 \\
7545\end{array}$ & $\begin{array}{l}\text { incomplete } \\
\text { incomplete }\end{array}$ & $\begin{array}{c}63,441 \\
546,849\end{array}$ & $\begin{array}{c}75,362 \\
554,394\end{array}$ \\
\hline
\end{tabular}

After initial automatic analysis of the qualified regions, detailed annotation of intact regions was conducted via Artemis and manual search with BLASTP. In addition, the data which indicated the presence of phage-borne DNA such as: (i) the presence of regions with higher $G+C$ pairs; (ii) the presence of phage recombinase gene-integrase; (iii) the presence of pathogenicity factors of viral origin; (iv) the presence of the cornerstones, were also included into the study [48,49]. The cornerstones are highly conserved phage specific proteins, which serve as indicators of the 
presence of a potential prophage: large terminase subunit, portal protein, head maturation protease, coat protein, tail shaft protein, tail fiber protein and tail tape measure protein. Especially distinctive are groups of large terminase subunits and portal proteins as conservative viral proteins [25].

Taking into consideration all aforementioned conditions, it has been showed that PHASTER annotation often differed substantially from manual result. Three main characteristics have been noted for PHASTER regions analysis: (i) it often classifies genes as viral, even if its homology to the database was minimal (less than 25\%); (ii) the gene sets in some regions either consist of multiple repeats of one gene or lack sufficient genes crucial for phage functioning; (iii) in contrast to the manual analysis, viral proteins were classified as phages specific to various bacterial taxonomical groups other than Burkholderia. Nonviral gene occurrence, gene repetitions and incorrect taxonomical affiliation of the genes were observed in the case of J2315_chr2_1, H111_chr1_3, 895_chr1_2, 895_chr1_3 and MSMB384WGS_chr1_2 regions which PHASTER marked as intact phages. Consequently, an additional group named by us as an artifact region (yellow) has been created. The artifact region group assembled all regions with homology less than $25 \%$ to the database or with gene set suggesting phage remnants.

In the case of two B. cenocepacia strains, J2315 and H111, a total of three phage regions have been already described in the literature. In B. cenocepacia J2315, chromosome 1, two prophages-KS10 (Goudie et al.) and Bcep-Mu (Summer et al.) were reported [50,51]. The third presided in the B. cenocepacia H111, chromosome 1- $\phi H 111-1$ (Lynch et al.) [29]. Even though the $\phi H 111-1$ was characterized thoroughly, its analysis was done based on the incomplete sequence of $B$. cenocepacia H111 (contigs). Because of that, the location of the $\phi H 111-1$ was suggested on the second chromosome. As our study was conducted on the complete sequence of B. cenocepacia H111, the location of the \$H111-1 could be indicated more precisely and was located on the first chromosome. [29]. Due to extensive characterization of regions containing KS10, BcepMu and $\phi H 111-1$ in the literature, they were treated as intact phages and included only in phylogenetic analysis.

The final count of prophages, based on both automated and manual methods, revealed fifteen intact, nine questionable and thirty-four incomplete phages (Table 2). Furthermore, five regions were classified as artifacts-J2315_chr2_1, H111_chr1_3, 895_chr1_2,895_chr1_3 and MSMB384WGS_chr1_2. Eight intact regions showed homology to Myoviridae (region homology ranged between $10.4 \%$ and $79.9 \%$ ), four were similar to Siphoviridae (homology between 1.7\% and 54.3\%). The remaining three phages, KS10 and Bcep-Mu are described as Myoviridae, while $\phi H 111-1$ belongs to Siphoviridae (Table S18). No correlation between host origin (CF or environmental) and number of phages have been detected.

Due to the observed differences between manual and automated annotation, the data obtained by both processes were compared in Tables S1-S16. PHASTER annotation occasionally did not indicate the gene function-only the gene number, such as gp12. To make the comparison table more consistent, a manual annotation was done for genes lacking a name, thus the basic information of the coding sequence was provided. This was done by a manual search of the databases for proteins with $100 \%$ homology or investigation of information stored in the NCBI database.

The interpretation of BLASTp results and occurrence of ORFs differed locally between manual and automatic annotation in all of analyzed genomes. Variations in genome start positions were noted for regions: 895_chr1_9, FL-5-3-30-S1-D7_chr1_2 and J2315_chr1_1. Furthermore, the latter phage also had an altered genome end position.

In most of the potential prophage genomes (except artifact regions) the differences in annotation were not sufficiently significant to change the final classification of prophage completeness. However, in the case of J2315_chr2_1, H111_chr1_3, 895_chr1_2,895_chr1_3 and MSMB384WGS_chr1_2 the result of the manual annotation led to a change of status from an intact to an artifact region.

Supplementary data (Tables S1-S16) were used to create the comparative maps (Figures S1-S16) depicting the constitution of each prophage genome. Figure 1 presents the comparative map of J2315_chr1_1 phage region, while the remaining maps are shown in Supplementary Materials (Figures S1-S16). Each image shows two variants of phage genome annotation and approximate location of prophage in the host chromosome. Most crucial genes with determined function are colored 
likewise on both annotation versions to provide further simplification of compared methods. Based on the results gathered in the Table 2, the genome maps depicting the location of identified regions was created with Circos (Figure 2).

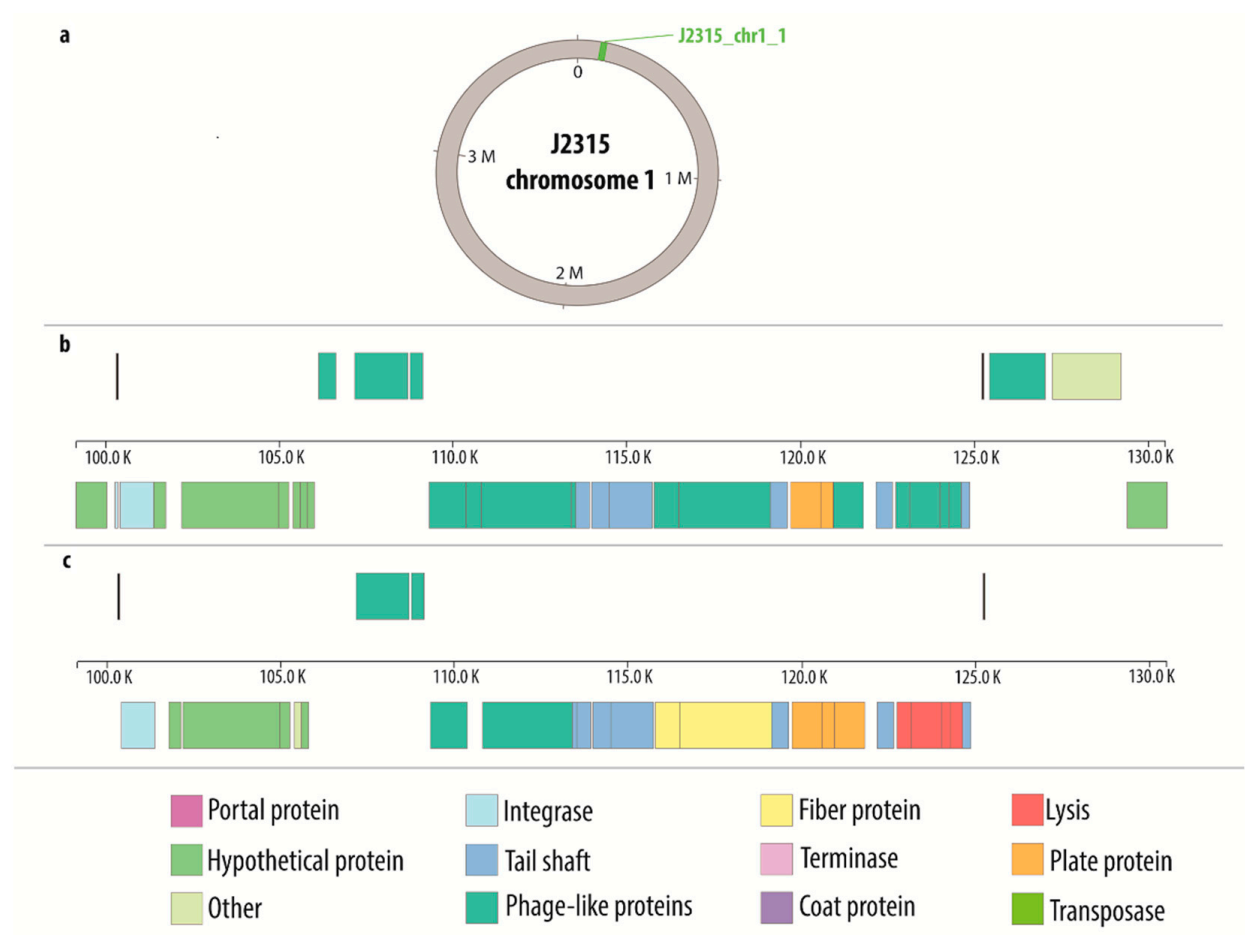

Figure 1. Comparative map of J2315_chr1_1 phage region: (a) general location of the phage on the host chromosome; (b) genes characterization based on PHASTER annotation; (c) genes characterization based on manual annotation.

The intact regions were compared with the BCC phages available in the NCBI database and with each other (Table S18). The inquiry against the database returned following results: (i) phages J2315_chr1_1 (41.28\%), 895_chr1_7 (33.54\%) and CR 318_chr1_1 (74.62\%) showed high similarity to phage KL3 (NC_015266.1); (ii) phages VC7848_chr1_2 (78.02\%) and MC0-3_chr1_1 (63.70\%) showed high similarity to phage AP3 (KP966108.1); (iii) phages DWS 37E-2_chr1 $(1.70 \%)$ and FL-5-3-30-S1-D7_chr1_2 (1.70\%) showed minimal similarity to phage phi1026b (NC_005284.1); (iv) phage 895_chr1_9 showed 54.29\% similarity to KS9 (NC_013055.1); (v) phage 895_chr2_1 showed 61.17\% similarity to ST79 (NC_021343.1); (vi) phage DDS 22E-1_chr1_2 showed 21.50\% similarity to phi644 (NC_009235.2); (vii) phage VC12308_chr1_1 showed 46.44\% similarity to phi52237 (NC_007145.2); while (vii)—phage 895_chr1_1 showed 79.90\% similarity to BcepMu (NC_005882.1). The comparison among studied phages showed a high similarity between phages J2315_chr1_1, VC12308_chr1_1 and 895_chr1_7. Another similar phages were MC0-3_chr1_1 and VC7848_chr1_1. The similarity between the other phages examined was not significant (Table S18).

Potential bacteriophages found in the bacterial genomes differed in the prevalence and distribution within host chromosomes. To investigate if there was any particular pattern in the placement of prophages in B. cenocepacia strains, the amount and location of prophage regions were examined. Table 3 presents the total prevalence of phage genomes in B. cenocepacia chromosomes. The occurrence of phages in hosts genomes varied from $0.3 \%$ to $3.67 \%$ of total DNA content, while the virus abundance in a single chromosome was between $0.3 \%$ up to $4.29 \%$. Regardless of the number of chromosomes in a particular strain, the majority of potential phage regions were always found in chromosome 1 . In 11 out of 12 strains possessing three chromosomes, most of prophage sequences were divided 
between chromosome 1 and 3, with a dominance of chromosome 1 (seven out of eleven). In the case of two-chromosome strains the ratio of phage to host sequence did not have any distinctive division.

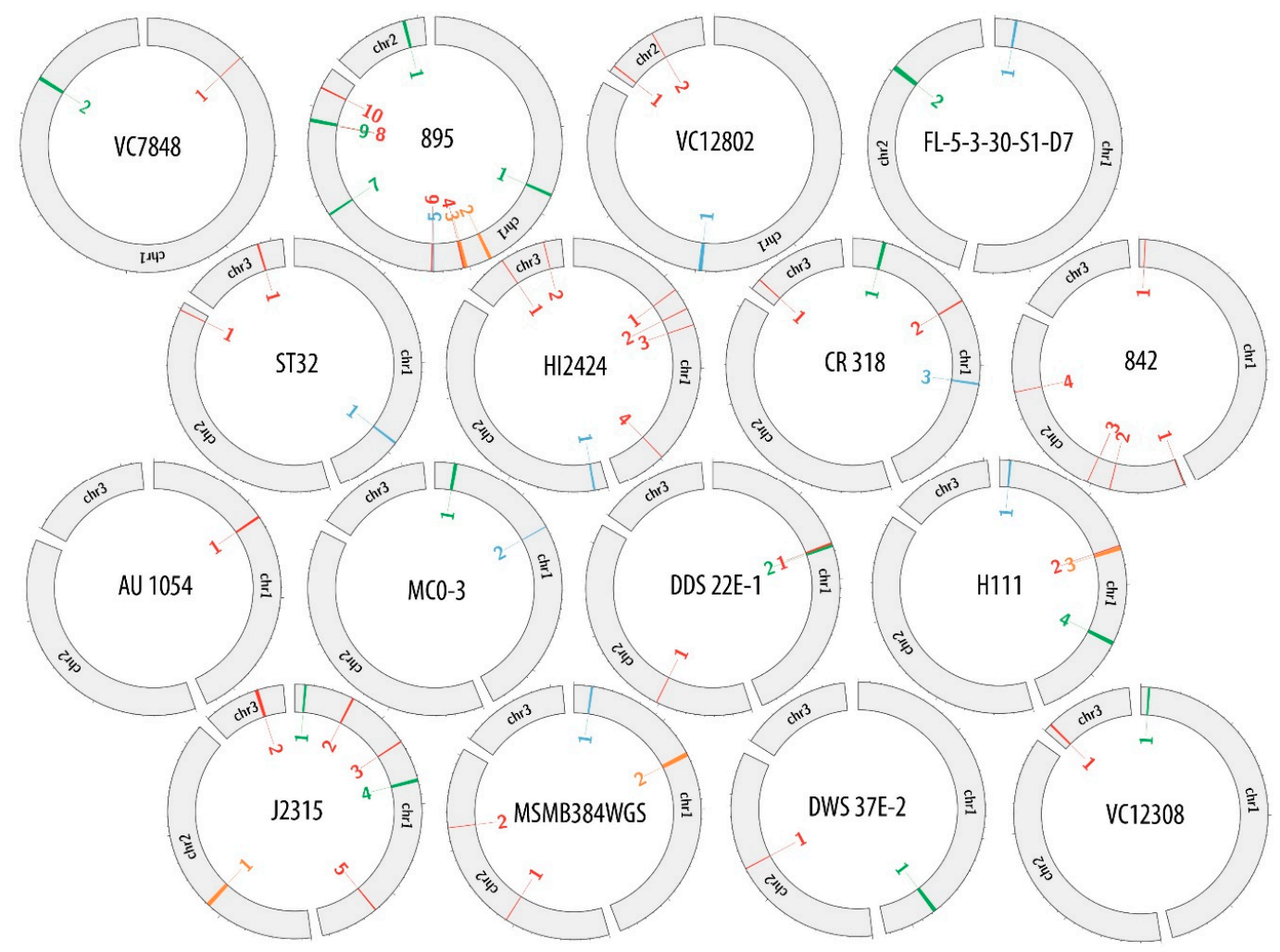

Figure 2. Genome maps of investigated B. cenocepacia strains depicting the location of found phage regions.

Table 3. The prevalence of prophages within B. cenocepacia genomes.

\begin{tabular}{|c|c|c|c|c|c|}
\hline Host & Chromosome & $\begin{array}{l}\text { Chromosome } \\
\text { Size (bp) }\end{array}$ & $\begin{array}{c}\text { Phage Prevalence } \\
\text { in Chromosome } \\
(\%)\end{array}$ & $\begin{array}{l}\text { Potential Phage } \\
\text { Regions } \\
\text { in Chromosome }\end{array}$ & $\begin{array}{c}\text { Total Phage } \\
\text { Prevalence in the } \\
\text { Host Genome (\%) }\end{array}$ \\
\hline \multirow{3}{*}{$\mathrm{J} 2315$} & 1 & $3,870,082$ & 2.99 & 5 & \multirow{3}{*}{2.51} \\
\hline & 2 & $3,217,062$ & 1.45 & 1 & \\
\hline & 3 & 875,977 & 4.29 & 1 & \\
\hline \multirow{3}{*}{ H111 } & 1 & $3,572,953$ & 3.24 & 4 & \multirow{3}{*}{1.50} \\
\hline & 2 & $3,102,677$ & - & 0 & \\
\hline & 3 & $1,039,263$ & - & 0 & \\
\hline \multirow{3}{*}{ DWS 37E-2 } & 1 & $3,241,886$ & 0.71 & 1 & \multirow{3}{*}{0.81} \\
\hline & 2 & $2,375,865$ & 0.36 & 1 & \\
\hline & 3 & 994,670 & - & 0 & \\
\hline \multirow{2}{*}{ FL-5-3-30-S1-D7 } & 1 & $3,461,321$ & 1.94 & 2 & \multirow{2}{*}{1.06} \\
\hline & 2 & $2,869,430$ & - & 0 & \\
\hline \multirow{2}{*}{895} & 1 & $7,459,003$ & 3.70 & 10 & \multirow{2}{*}{3.67} \\
\hline & 2 & $1,072,666$ & 3.51 & 1 & \\
\hline \multirow{3}{*}{ ST32 } & 1 & $3,822,749$ & 0.67 & 1 & \multirow{3}{*}{0.69} \\
\hline & 2 & $3,086,109$ & 0.34 & 1 & \\
\hline & 3 & 989,585 & 2.08 & 1 & \\
\hline \multirow{3}{*}{842} & 1 & $3,526,250$ & 0.28 & 1 & \multirow{3}{*}{0.54} \\
\hline & 2 & $3,107,451$ & 1.07 & 4 & \\
\hline & 3 & $1,271,875$ & - & 0 & \\
\hline
\end{tabular}


Table 3. Cont.

\begin{tabular}{|c|c|c|c|c|c|}
\hline Host & Chromosome & $\begin{array}{l}\text { Chromosome } \\
\text { Size (bp) }\end{array}$ & $\begin{array}{c}\text { Phage Prevalence } \\
\text { in Chromosome } \\
(\%)\end{array}$ & $\begin{array}{l}\text { Potential Phage } \\
\text { Regions } \\
\text { in Chromosome }\end{array}$ & $\begin{array}{c}\text { Total Phage } \\
\text { Prevalence in the } \\
\text { Host Genome (\%) }\end{array}$ \\
\hline \multirow{3}{*}{ MSMB384WGS } & 1 & $3,588,848$ & 2.04 & 2 & \multirow{3}{*}{1.15} \\
\hline & 2 & $3,069,864$ & 0.52 & 2 & \\
\hline & 3 & $1,121,886$ & - & 0 & \\
\hline \multirow{3}{*}{ HI2424 } & 1 & $3,483,902$ & 0.95 & 4 & \multirow{3}{*}{0.93} \\
\hline & 2 & $2,998,664$ & 0.69 & 1 & \\
\hline & 3 & $1,055,417$ & 1.60 & 2 & \\
\hline \multirow{3}{*}{ CR 318} & 1 & $3,511,146$ & 2.21 & 3 & \multirow{3}{*}{1.27} \\
\hline & 2 & $3,097,552$ & - & 0 & \\
\hline & 3 & $1,056,196$ & 1.84 & 3 & \\
\hline \multirow{3}{*}{ AU 1054} & 1 & $3,294,563$ & 0.73 & 1 & \multirow{3}{*}{0.30} \\
\hline & 2 & $2,788,459$ & - & 0 & \\
\hline & 3 & $1,196,094$ & - & 0 & \\
\hline \multirow{3}{*}{ MC0-3 } & 1 & $3,532,883$ & 1.40 & 2 & \multirow{3}{*}{0.62} \\
\hline & 2 & $3,213,911$ & - & 0 & \\
\hline & 3 & $1,224,595$ & - & 0 & \\
\hline \multirow{3}{*}{ DDS 22E-1 } & 1 & $3,668,832$ & 1.52 & 2 & \multirow{3}{*}{0.80} \\
\hline & 2 & $3,209,624$ & 0.30 & 1 & \\
\hline & 3 & $1,166,794$ & - & 0 & \\
\hline VC7848 & 1 & $7,499,459$ & 0.60 & 2 & 0.60 \\
\hline \multirow{3}{*}{ VC12308 } & 1 & $3,668,000$ & 0.62 & 1 & \multirow{3}{*}{0.56} \\
\hline & 2 & $2,984,720$ & - & 0 & \\
\hline & 3 & 964,521 & 2.12 & 1 & \\
\hline \multirow{2}{*}{ VC12802 } & 1 & $6,339,862$ & 0.61 & 1 & \multirow{2}{*}{0.79} \\
\hline & 2 & $1,055,047$ & 1.84 & 2 & \\
\hline
\end{tabular}

To investigate prophage integration sites in the host chromosomes we manually examined their adjacent regions in the adjacent neighborhood. This verification was done regardless of the region status (intact, incomplete, questionable, artifact) (Table S18). Two approaches were used. First, we determined single genes located next to start and end positions. Second, we considered the 5-10 $\mathrm{kb}$ region located next to phage genome start and end. The first study aimed to search for a pattern in integration site (similar neighboring gene). The second method sought to verify the positioning of the start and end positions which were determined automatically by PHASTER. If the verification showed the presence of additional phage-like genes, the appropriate change was done in manual version of annotation. In most cases the phage genomes started and ended in the intergenic space. There were however several exceptions: (i) start position of prophage regions located inside the host gene were observed for J2315_chr1_2, 895_chr1_3, 895_chr1_4, HI2424_chr2_1, HI2424_chr3_1, DDS 22E-1_chr2_1; (ii) end position of prophage regions located inside the host gene were observed for DWS 37E-2_chr1_1, 895_chr1_3, 895_chr1_8 and VC12308_chr1_1; (iii) both, start and end positions of prophage regions located inside the host gene were observed for 895_chr1_3 (artifact region).

The closest neighbors of phage regions were often hypothetical proteins, which flanked phage genomes in 48 cases $(37.2 \%)$. The most common neighboring, recognizable sequence (non-hypothetical protein), was tRNA-Arg, which was found either upstream or downstream of the prophage sequence (10.3\% of all regions). The second group of sequences located next to identified regions was $\mathrm{ABC}$ transporter genes (4.7\% of all regions), while the third one was LysR family transcriptional regulator genes $(4 \%)$. Peptidase encoding genes were found in the neighborhood of three phage regions (2.4\%). The remaining 52 flanking genes $(41.4 \%)$ have determined function, however they did not repetitively appear as neighboring sequences (Table S18).

Bacteriophages can encode virulence factors such as toxins, enzymes or drug resistance. As bacteria may domesticate phages by leaving only useful genes, all identified prophage regions (complete, questionable, artifact, incomplete) were analyzed for the presence of potential virulence 
genes (Table 4). Thirteen genes were recognized as sequences potentially increasing bacterial drug resistance: (i) one was specified as class A $\beta$-lactamase; (ii) one was the Vicinal Oxygen Chelate (VOC) family protein; (iii) eleven belonged to the Major Facilitator Superfamily (MFS) transporter superfamily. VOC proteins possess Glo_EDI_BRP_like domains, which are found in a vast variety of related groups of metalloproteins. One of these groups comprised of antibiotic resistance proteins which can block drugs in different ways. For example, bleomycin resistance protein inhibits drug activity by binding to it, while fosfomycin resistance proteins inactive the drug by modifying its molecule [52,53].

The MFS transporters are the largest known superfamily of secondary carriers [54]. A considerable amount of drug and multidrug efflux pumps found in bacteria are comprised of the MFS transporters class. They are found in both Gram-negative (e.g., enterobacteria, Pseudomonas sp. or Moraxella sp.) and Gram-positive strains (Staphylococcus sp., Bacillus sp.), however it is unclear if they share substrate profiles [55]. The MFS found in strains examined have been phylogenetically compared to each other (Figure 3). Although, MFS proteins occur six times in the analyzed regions of HI2424, they differ significantly. There is however high similarity between MFS transporters found in VC12802_chr2_2, CR318_chr3_2 and HI2424_chr3_2 (undelined in Table 4).

Table 4. Potential virulence factors located in found regions. Regions types were marked with colors: intact (green), questionable (blue), incomplete (red) and artifact region (yellow).

\begin{tabular}{cccccc}
\hline Region & Start & End & Product & Virulence Effect & Accession \\
\hline J2315_chr2_1 & 12,317 & 12,700 & Fic & TA system compound & WP_006488862.1 \\
842_chr2_1 & 6642 & 7541 & class A $\beta$-lactamase & drug resistance & WP_034202207.1 \\
842_chr2_2 & 2065 & 3390 & MFS transporter & drug resistance/virulence & WP_006495119.1 \\
MSMB384WGS_chr2_1 & 1 & 1500 & MFS transporter & drug resistance/virulence & WP_060268128.1 \\
MSMB384WGS_chr2_1 & 2697 & 3080 & VOC family protein & drug resistance/virulence & WP_060268132.1 \\
HI2424_chr1_2 & 1 & 1311 & MFS transporter* (a) & drug resistance/virulence & WP_011545048.1 \\
HI2424_chr1_2 & 3764 & 4969 & MFS transporter * (b) & drug resistance/virulence & WP_011545051.1 \\
HI2424_chr1_3 & 1039 & 2301 & MFS transporter & drug resistance/virulence & WP_011545193.1 \\
HI2424_chr1_4 & 2829 & 4004 & MFS transporter & drug resistance/virulence & WP_011694391.1 \\
HI2424_chr2_1 & 3597 & 4892 & MFS transporter & drug resistance/virulence & WP_011548498.1 \\
HI2424_chr3_2 & 3269 & 4666 & MFS transporter & drug resistance/virulence & WP_011695034.1 \\
CR 318_chr3_2 & 1499 & 2896 & MFS transporter & drug resistance/virulence & WP_011695034.1 \\
DDS 22E-1_chr1_2 & 9157 & 9552 & HicB & TA system compound & AJT61392.1 \\
DDS 22E-1_chr1_2 & 9577 & 9759 & HicA & TA system compound & ADF59182.1 \\
VC7848_chr1_1 & 5764 & 7080 & MFS transporter & drug resistance/virulence & WP_011548265.1 \\
VC12802_chr2_2 & 1499 & 2896 & MFS transporter & drug resistance/virulence & WP_077217595.1 \\
\hline & * In region HI2424_chr1 2 two different MFS transporters were found &
\end{tabular}

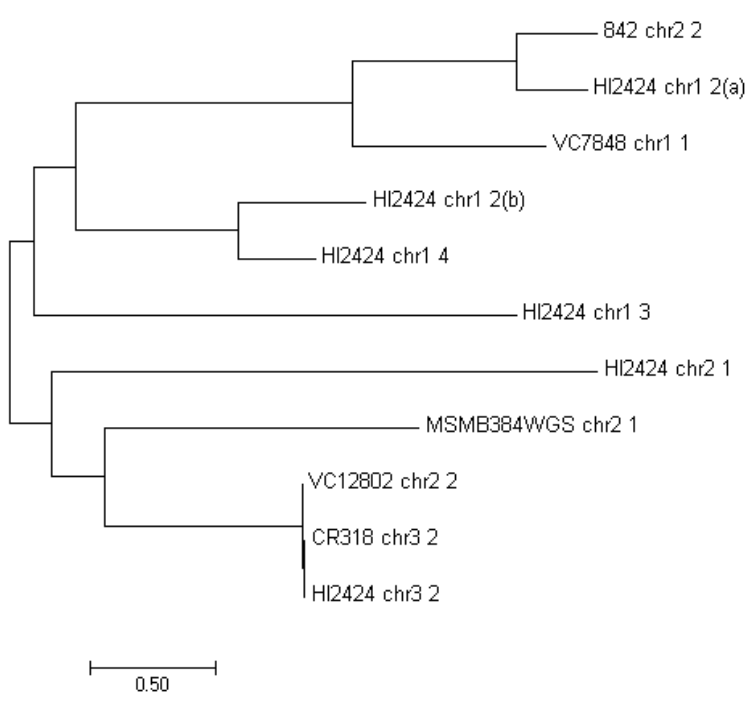

Figure 3. Maximum likelihood comparison of the MFS proteins found in examined strains. 
Three genes encoded for toxin-antitoxin (TA) systems (Table 4). The hicA and hicB found in DDS 22E-1_chr1_2 encode a complete two protein system that targets mRNA. HicA is the predicted interferase, while HicB balances the system and neutralizes HicA [56]. Interestingly, the only complete TA system was found in intact phage DDS 22E-1_chr1_2. This may suggest that the host is not able to remove or damage the phage because the system is active.

Bacteria can be armed with antiphage defense systems such as CRISPR-Cas and BREX, which effectively protect its host against viral infections [57]. Those systems may also take part in disposing of integrated phages (completely or partially), leading to the creation of cryptic phages [58]. Consequently, all bacterial genomes were screened for the presence of these bacterial antiphage defense systems. No BREX systems were found after manual analysis based on previously described methodology [59]. In contrast, using CRISPRfinder [60] ten potential CRISPR sequences were located in the chromosomes of B. cenocepacia strain 842 (two sequences in the same chromosome), J2315, H111, DWS 37E-2, 895, ST32, MSMB384WGS, CR318, DDS 22E-1, and VC7848 strains. Table S19 presents detailed data considering each of potential CRISPR sequence (Supplementary Data).

In an attempt to differentiate taxonomical groups of analyzed prophages, a phylogenetic analysis was conducted. The evolutionary resemblance of 64 nucleotide phage-like sequences (intact, artifact, questionable, incomplete) were proposed by using the maximum likelihood method based on the Tamura-Nei model [61]. The tree with the highest log likelihood $(-108,132.8877)$ is presented in Figure 4. The tree is drawn to scale, with branch lengths measured in the number of substitutions per site.

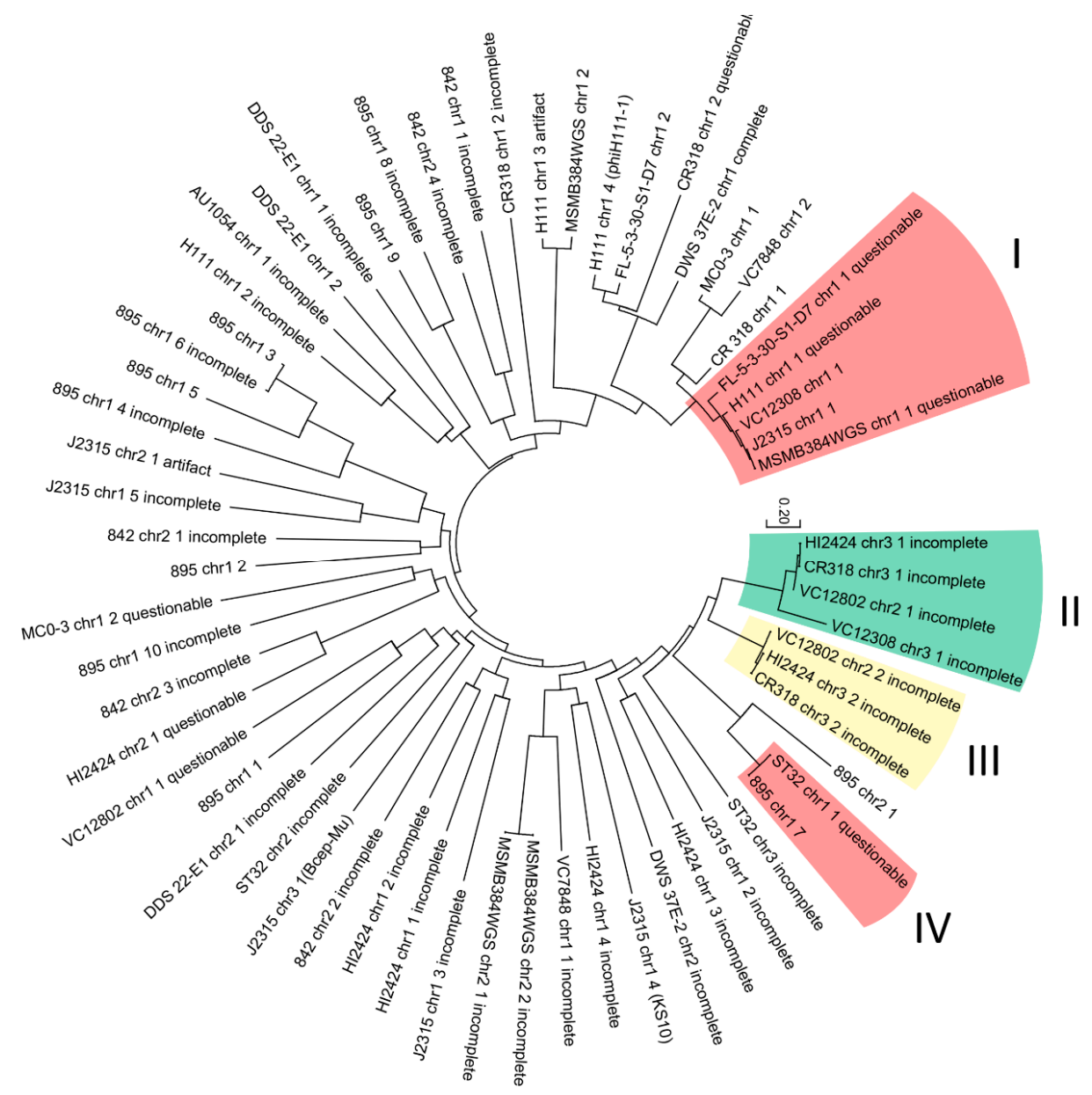

Figure 4. Maximum likelihood comparison of 64 nucleotide phage-like sequences found in B. cenocepacia strains. 
Four specific clades were distinguished. Phage genomes located in selected clades (marked on the tree) share the same neighboring sequence in the host genome: clade I and IV-tRNA-Arg; clade II-dehydrogenase family proteins; clade III-ABC transporter substrate-binding proteins. Other branches did not show any significant internal resemblance.

To summarize the results obtained by automatic and manual methods, region characteristics cards were created for all intact and artifact regions (Supplementary data). The cards collect the most crucial data relating to each of the qualified phages. The intact phage card consists of basic data including size and location, taxonomical affiliation (based on the homology the NCBI database), the number of ORFs annotated, recognized regulatory sequences, region derivation and the complete annotation. Information regarding regulatory sequences and taxonomy are not included in artifact region cards however the additional data including homology of each protein is appended to the annotation tables.

\section{Discussion}

This article presents the results of an in silico analysis of potential prophage regions found in Burkholderia cenocepacia genomes, currently stored in the NCBI database (October 2017). Regions were divided into four groups basing on their completeness: intact (15 regions), questionable (nine regions), incomplete (34 regions) and artifact (five regions). Phage prevalence differed between BCC strains but did not exceed $3.67 \%$ of the total genome size, which is relatively low ratio in comparison to reports by Ohnishi et al. and Beres et al. considering different bacterial genus, such as E. coli O157 or M3 MGAS 315 (12\% of the chromosome) [62,63].

All regions were subjected to both automatic and manual annotation processes to see if there were notable differences in these techniques. The automatic method was fast and allowed rough annotations, but it was quite imprecise because of incorrect interpretation of the homology level between genes in regions and in the database. Even if the genes' similarity to the virus database was at an insignificant level (in some cases as low as 5\%) the software identified the gene as viral. In the PHASTER scoring method some regions consisting of multiple repeats of the same virus gene were eventually marked as intact prophages. Bearing that in mind, the automatic annotation was verified manually, resulting in localization of potential mistakes made by the software and allowing the creation of an additional group of artifact regions. Those regions were either incomplete prophages with essential genes deprived or were aggregates of random viral-origin genes (often repetitive). The occurrence of such regions may suggest that BCC strains are able to domesticate prophages, as described previously by Bobay et al. [27].

Recently, Bodilis et al. 2018 [63] compared the Burkholderia ET12 lineage with a selection of environmental strains, including similar analysis based on the PHASTER software. These results considering fully sequences strains (J2315, MC0-3 and AU1054) presented by Bodilis et al. 2018 [63] were partially synonymous with the ones obtained in this study: (i) J2315_chr1_1 is the same region as the PI_J2315_1; (ii) J2315_chr2_1 is the same region as the PI_J2315_3; (iii) both prophages which were already described (KS10 and BcepMu) have been annotated in the same regions by all studies [50,51]; (iv) regions MC0-3_chr1_1 and MC0-3_chr1_2 are the same regions respectively to PI_MC0-3_1 and PI_MC0-3_2. Regions PI_J2315_6, PI_MC0-3_3, PI_MC0-3_4 and PI_AU1054_1 presented by Bodilis et al. 2018 [63] could not be found with the current version of PHASTER, while region PI_J2315_4 (ORFs BCAM0001AM_1973-BCAM0001AM_2038) is no longer available in the database, making it impossible to address those regions in the comparison. Further, all data relating to the H111 genome were based on the contigs sequence and therefore, the PI_H111_1, PI_H111_2 and PI_H111_3 regions could not be located in current database. Additionally, the size of the region PI_H111_3 which has been described as phage $\phi \mathrm{H} 111-1$ does not match the region size from our study and Lynch et al. description (10.8 kB vs. $43.0 \mathrm{kB})[29,64]$.

A search for virulence factors was conducted in all regions to examine eventual influence of prophage to host pathogenicity. The results obtained suggest that prophages of Burkholderia 
preferentially carry drug resistance mechanisms over other categories of virulence factors. This finding is consistent to those of Summer et al. and Ronning et al. [21,65].

The resistance of $B C C$ to $\beta$-lactams is well-known, however there are no reports on these genes being located on the prophage region [62]. We now show that a class $A \beta$-lactamase encoding gene was identified in 842_chr2_1 region. MFS transporter genes were the most commonly observed in BCC genomes analyzed which is probably related to host drug resistance. MFS have a very broad substrate spectrum, thus their influence on the host virulence could not be precisely indicated. DeShazer examined the influence of MFC genes deletions in B. mallei prophage phi1026b extensively, however no correlation to the host virulence was observed [66].

Three of the identified genes-fic (J2315_chr2_1), hicA and hicB (DDS 22E-1_chr1_2), encode components of toxin-antitoxin systems. Fic is a representative of incomplete Fic/Doc system, whereas hic $\mathrm{A}$ and hicB form a complete hic $\mathrm{AB}$ cassette. The Hic $\mathrm{AB}$ cassette has been extensively described and classified as a type II toxin-antitoxin system [67]. HicA serves as a ribosome-independent mRNA interferase, which can cleave specific mRNAs and tmRNAs. HicB function as antitoxin and is composed of two domains, a DNA-recognition domain (C-terminal) and an RNase $\mathrm{H}$ fold with no catalytic residues (N-terminal). The HicAB cassette was previously identified as a part of bacteria (including Burkholderia species) or prophage genomes [56,68]. What is more, the HicA protein, found in Burkholderia pseudomallei, was proven to play a role in formation of the persister cells tolerant to ciprofloxacin and ceftazidime [69]. There are no reports of locating a HicAB cassette directly in a Burkholderia prophage.

The virulence of B. cenocepacia strains HI2424, AU1054 and J2315 was tested in the nematode Caenorhabditis elegans model by Cooper et al. 2009 [69]. It was showed that two closely related B. cenocepacia isolates of the PHDC clonal lineage, HI2424 and AU1054, exhibited significantly different virulence, with HI2424 being more lethal and toxic to the nematodes. When considered in relation to our study, it could be inferred that strains possessing more prophage regions are more virulent/toxic [70].

The results obtained from the CRISPR system search did not show any direct correlation between the host and its prophages. The number of phages identified and their completeness differed between hosts possessing CRISPR system. The $65 \%$ of the CRISPR systems found were located on the second chromosome, which was the least favored prophage integration place (based on the prophage prevalence and distribution). If the strain carried CRISPR on the second chromosome there were no prophages present or only incomplete ones. The results indicating the presence of CRISPR differed from the study of Bodilis et al. 2018 [64]. While the absence of CRISPR in H111 may be explained by the incomplete sequence of H111, the lack of the anti-phage system in J2315 is more difficult to interpret. The most probable reason is the use of a more recent version of the CRISPRfinder which is more effective in searching for these systems.

The closest neighborhood analysis showed that the biggest fraction of repetitive sequences found next to the prophage regions was tRNA-Arg. The tRNAs are known to be the most common integration sites of prophages, including BCC hosts. Previously described tRNA that are known to be valid recombination sites are tRNA-Arg (Roszniowski et al.), tRNA-Thr (Lynch et al.), tRNA-Phe (Ronning et al.) and tRNA-Ser (Holden et al.) [29,65,71,72]. Even though the ABC transporter, LysR family transcriptional regulators and peptidase encoding genes were found in the phage neighborhood less frequently than tRNA-Arg, their continual appearance, may suggest these are also plausible integration sites for viruses (Table S18).

In summary, the prophages identified in the B. cenocepacia genomes analyzed differed in amount, composition and completeness. The biggest proportion of located viruses were marked as incomplete, which may suggest that this host is actively domesticating its prophages. The fact that BCC are environmental bacteria associated with the rhizosphere also suggests that it will favor collection of phage genes, as they may promote the fitness in their habitat. The analyses allowed antiphage systems to be distinguished as well as phage genes, which are potentially responsible for host virulence (drug resistance, pathogenicity). The results obtained offer profound insights into the composition of 
each phage genome, which are future targets for research, and will enable the selection of appropriate methods and build a solid foundation for further experimental work in relatively cost-efficient and quick manner.

Supplementary Materials: The following are available online at http:/ / www.mdpi.com/1999-4915/10/6/297/s1: Table S1: Prophages BBC, Table S2: Method comparison 895_chr1_1, Table S3: Method comparison 895_chr1_2, Table S4: Method comparison 895_chr1_3, Table S5: Method comparison 895_chr1_7, Table S6: Method comparison 895_chr1_9, Table S7: Method comparison 895_chr2_1, Table S8: Method comparison CR 318_chr1_1, Table S9: Method comparison DDS 22E-1_chr1_2, Table S9: Method comparison DWS 37E-2_chr1_1, Table S11: Method comparison FL-5-3-30-S1-D7_chr1_1, Table S12: Method comparison J2315_chr1_1, Table S13: Method comparison J2315_chr2_1, Table S14: Method comparison MC0-3_chr1_1, Table S15: Method comparison MSMB384WGS_chr1_2, Table S16: Method comparison VC7848_chr1_2, Table S17: Method comparison VC12308_chr1_1, Table S18: Prophage presence complete, Table yS19: CRISPR regions, Supplementary data 1: RC 895_chr1_1, Supplementary data 2: RC 895_chr1_2, Supplementary data 3: RC 895_chr1_3, Supplementary data 4: RC 895_chr1_7, Supplementary data 5: RC 895_chr1_9, Supplementary data 6: RC 895_chr2_1, Supplementary data 7: RC CR 318_chr1_1, Supplementary data 8: RC DDS 22E-1_chr1_2, Supplementary data 9: RC DWS 37E-2_chr1_1, Supplementary data 10: RC FL-5-3-30-S1-D7_chr1_2, Supplementary data 11: RC H111_chr1_3, Supplementary data 12: RC J2315_chr1_1, Supplementary data 13: RC J2315_chr2_1, Supplementary data 14: RC MC0-3_chr1_1, Supplementary data 15: RC MSMB384WGS_chr1_2, Supplementary data 16: RC VC7848_chr1_2, Supplementary data 17: RC VC12308_chr1_1, Figure S1: J2315_chr2_1 linear maps, Figure S2: H111_chr1_3 linear maps, Figure S3: DWS 37E-2_chr1_1 linear maps, Figure S4: VC12308_chr1_1 linear maps, Figure S5: FL-5-3-30-S1-D7_chr1_2 linear maps, Figure S6: 895_chr1_1 linear maps, Figure S7: 895_chr1_2 linear maps, Figure S8: 895_chr1_3 linear maps, Figure S9: 895_chr1_7 linear maps, Figure S10: 895_chr1_9 linear maps, Figure S11: 895_chr2_1 linear maps, Figure S12: MSMB384WGS_chr1_2 linear maps, Figure S13: CR 318_chr1_1 linear maps, Figure S14: MC0-3_chr1_1 linear maps, Figure S15: DDS 22E-1chr1_2 linear maps, Figure S16: VC7848_chr1_2 linear maps.

Author Contributions: B.R. performed the experiments and analyzed the data, Z.D.-K. conceived and designed the analyses; B.R., Z.D.-K. and S.M.C. wrote the paper.

Acknowledgments: No special funds have been received for covering the costs to publish in open access.

Conflicts of Interest: The authors declare no conflicts of interest.

\section{References}

1. Burkholder, W.H. Three bacterial plant pathogens: Phytomonas caryophylli, sp. n., Phytomonas alliicola sp. n., and Phytomonas manihotis (Artaud, Berthet and Bondar) Viégas. Phythopathology 1942, 57, 141-149.

2. Yabuuchi, E.; Kosako, Y.; Oyaizu, H.; Yano, I.; Hotta, H.; Hashimoto, Y.; Ezaki, T.; Arakawa, M. Proposal of Burkholderia gen. nov. and transfer of seven species of the genus Pseudomonas homology group II to the new genus, with the type species Burkholderia cepacia (Palleroni and Holmes 1981) comb. nov. Microbiol. Immunol. 1992, 36, 1251-1275. [CrossRef] [PubMed]

3. Chiarini, L.; Bevivino, A.; Dalmastri, C.; Tabacchioni, S.; Visca, P. Burkholderia cepacia complex species: Health hazards and biotechnological potential. Trends Microbiol. 2006, 14, 277-286. [CrossRef] [PubMed]

4. Jacobs, J.L.; Fasi, A.C.; Ramette, A.; Smith, J.J.; Hammerschmidt, R.; Sundin, G.W. Identification and onion pathogenicity of Burkholderia cepacia complex isolates from the onion rhizosphere and onion field soil. Appl. Environ. Microbiol. 2008, 74, 3121-3129. [CrossRef] [PubMed]

5. Coventry, H.S.; Dubery, I.A. Lipopolysaccharides from Burkholderia cepacia contribute to an enhanced defensive capacity and the induction of pathogenesis-related proteins in Nicotianae tabacum. Physiol. Mol. Plant Pathol. 2001, 58, 149-158. [CrossRef]

6. Vandamme, P.; Holmes, B.; Vancanneyt, M.; Coenye, T.; Hoste, B.; Coopman, R.; Revets, H.; Lauwers, S.; Gillis, M.; Kersters, K.; et al. Occurrence of multiple genomovars of Burkholderia cepacia in cystic fibrosis patients and proposal of Burkholderia multivorans sp. nov. Int. J. Syst. Bacteriol. 1997, 47, 1188-1200. [CrossRef] [PubMed]

7. Courtney, J.; Dunbar, K.E.; McDowell, A.; Moore, J.; Warke, T.; Stevenson, M.; Elborn, J. Clinical outcome of Burkholderia cepacia complex infection in cystic fibrosis adults. J. Cyst. Fibros. 2004, 3, 93-98. [CrossRef] [PubMed]

8. Folescu, T.W.; da Costa, C.H.; Cohen, R.W.F.; da Conceição Neto, O.C.; Albano, R.M.; Marques, E.A. Burkholderia cepacia complex: Clinical course in cystic fibrosis patients. BMC Pulm. Med. 2015, 15, 158. [CrossRef] [PubMed] 
9. Chernish, R.N.; Aaron, S.D. Approach to resistant Gram-negative bacterial pulmonary infections in patients with cystic fibrosis. Curr. Opin. Pulm. Med. 2003, 9, 509-515. [CrossRef] [PubMed]

10. Beckman, W.; Lessie, T.G. Response of Pseudomonas cepacia to $\beta$-lactam antibiotics: Utilization of penicillin G as the carbon source. J. Bacteriol. 1979, 140, 1126-1128. [PubMed]

11. Taylor, K.; McCullough, B.; Clarke, D.J.; Langley, R.J.; Pechenick, T.; Hill, A.; Campopiano, D.J.; Barran, P.E.; Dorin, J.R.; Govan, J.R.W. Covalent dimer species of $\beta$-defensin Defr1 display potent antimicrobial activity against multidrug-resistant bacterial pathogens. Antimicrob. Agents Chemother. 2007, 51, 1719-1724. [CrossRef] [PubMed]

12. Leitão, J.H.; Sousa, S.A.; Ferreira, A.S.; Ramos, C.G.; Silva, I.N.; Moreira, L.M. Pathogenicity, virulence factors, and strategies to fight against Burkholderia cepacia complex pathogens and related species. Appl. Microbiol. Biotechnol. 2010, 87, 31-40. [CrossRef] [PubMed]

13. McClean, S.; Callaghan, M. Burkholderia cepacia complex: Epithelial cell-pathogen confrontations and potential for therapeutic intervention. J. Med. Microbiol. 2009, 58, 1-12. [CrossRef] [PubMed]

14. Saldias, M.S.; Valvano, M.A. Interactions of Burkholderia cenocepacia and other Burkholderia cepacia complex bacteria with epithelial and phagocytic cells. Microbiology 2009, 155, 2809-2817. [CrossRef] [PubMed]

15. Hutchison, M.L.; Bonell, E.C.; Poxton, I.R.; Govan, J.R. Endotoxic activity of lipopolysaccharides isolated from emergent potential cystic fibrosis pathogens. FEMS Immunol. Med. Microbiol. 2000, 27, 73-77. [CrossRef] [PubMed]

16. Venturi, V.; Friscina, A.; Bertani, I.; Devescovi, G.; Aguilar, C. Quorum sensing in the Burkholderia cepacia complex. Res. Microbiol. 2004, 155, 238-244. [CrossRef] [PubMed]

17. Whitby, P.W.; VanWagoner, T.M.; Taylor, A.A.; Seale, T.W.; Morton, D.J.; LiPuma, J.J.; Stull, T.L. Identification of an RTX determinant of Burkholderia cenocepacia J2315 by subtractive hybridization. J. Med. Microbiol. 2006, 55, 11-21. [CrossRef] [PubMed]

18. Engledow, A.S.; Medrano, E.G.; Mahenthiralingam, E.; LiPuma, J.J.; Gonzalez, C.F. Involvement of a plasmid-encoded type IV secretion system in the plant tissue watersoaking phenotype of Burkholderia cenocepacia. J. Bacteriol. 2004, 186, 6015-6024. [CrossRef] [PubMed]

19. Sajjan, S.U.; Carmody, L.A.; Gonzalez, C.F.; LiPuma, J.J. A type IV secretion system contributes to intracellular survival and replication of Burkholderia cenocepacia. Infect. Immun. 2008, 76, 5447-5455. [CrossRef] [PubMed]

20. Caraher, E.; Reynolds, G.; Murphy, P.; McClean, S.; Callaghan, M. Comparison of antibiotic susceptibility of Burkholderia cepacia complex organisms when grown planktonically or as biofilm in vitro. Eur. J. Clin. Microbiol. Infect. Dis. 2007, 26, 213-216. [CrossRef] [PubMed]

21. Summer, E.J.; Gill, J.J.; Upton, C.; Gonzalez, C.F.; Young, R. Role of phages in the pathogenesis of Burkholderia, or 'Where are the toxin genes in Burkholderia phages?'. Curr. Opin. Microbiol. 2007, 10, 410-417. [CrossRef] [PubMed]

22. Wilhelm, S.W.; Suttle, C.A. Viruses and nutrient cycles in the sea. Bioscience 1999, 49, 781-788. [CrossRef]

23. Clokie, M.R.; Millard, A.D.; Letarov, A.V.; Heaphy, S. Phages in nature. Bacteriophage 2011, 1, 31-45. [CrossRef] [PubMed]

24. Ubukata, K.; Konno, M.; Fujii, R. Transduction of drug resistance to tetracycline, chloramphenicol, macrolides, lincomycin and clindamycin with phages induced from Streptococcus pyogenes. J. Antibiot. 1975, 28, 681-688. [CrossRef] [PubMed]

25. Casjens, S. Prophages and bacterial genomics: What have we learned so far? Mol. Microbiol. 2003, 49, 277-300. [CrossRef] [PubMed]

26. Campbell, A.M. Cryptic prophages. In Escherichia coli and Salmonella: Cellular and Molecular Biology; Neidhardt, F.C., Curtiss, R., III, Ingraham, J.L., Lin, E.C.C., Low, K.B., Magasanik, B., Reznikoff, W.S., Riley, M., Schaechter, M., Umbarger, H.E., Eds.; ASM Press: Washington, DC, USA, 1996; pp. 2041-2046.

27. Bobay, L.-M.; Touchon, M.; Rocha, E.P.C. Pervasive domestication of defective prophages by bacteria. Proc. Natl. Acad. Sci. USA 2014, 111, 12127-12132. [CrossRef] [PubMed]

28. Krupovic, M.; Prangishvili, D.; Hendrix, R.W.; Bamford, D.H. Genomics of bacterial and archaeal viruses: Dynamics within the prokaryotic virosphere. Microbiol. Mol. Biol. Rev. 2011, 75, 610-635. [CrossRef] [PubMed]

29. Lynch, K.H.; Liang, Y.; Eberl, L.; Wishart, D.S.; Dennis, J.J. Identification and characterization of $\phi H 111-1$. Bacteriophage 2013, 3, e26649. [CrossRef] [PubMed] 
30. Holden, M.T.G.; Seth-Smith, H.M.B.; Crossman, L.C.; Sebaihia, M.; Bentley, S.D.; Cerdeno-Tarraga, A.M.; Thomson, N.R.; Bason, N.; Quail, M.A.; Sharp, S.; et al. The genome of Burkholderia cenocepacia J2315, an epidemic pathogen of cystic fibrosis patients. J. Bacteriol. 2009, 191, 261-277. [CrossRef] [PubMed]

31. Arndt, D.; Grant, J.R.; Marcu, A.; Sajed, T.; Pon, A.; Liang, Y.; Wishart, D.S. PHASTER: A better, faster version of the PHAST phage search tool. Nucleic Acids Res. 2016, 44, W16-W21. [CrossRef] [PubMed]

32. NCBI. NCBI-Complete Virus Genomes Table. Available online: https:/ / www.ncbi.nlm.nih.gov/genomes/ GenomesGroup.cgi?taxid=10239\&opt=Virus\&sort=genome (accessed on 31/05/2017).

33. Zhou, Y.; Liang, Y.; Lynch, K.H.; Dennis, J.J.; Wishart, D.S. PHAST: A fast phage search tool. Nucleic Acids Res. 2011, 39, W347-W352. [CrossRef] [PubMed]

34. Rutherford, K.; Parkhill, J.; Crook, J.; Horsnell, T.; Rice, P.; Rajandream, M.A.; Barrell, B. Artemis: Sequence visualization and annotation. Bioinformatics 2000, 16, 944-945. [CrossRef] [PubMed]

35. Besemer, J.; Lomsadze, A.; Borodovsky, M. GeneMarkS: A self-training method for prediction of gene starts in microbial genomes. Implications for finding sequence motifs in regulatory regions. Nucleic Acids Res. 2001, 29, 2607-2618. [CrossRef] [PubMed]

36. Altschul, S.F.; Gish, W.; Miller, W.; Myers, E.W.; Lipman, D.J. Basic local alignment search tool. J. Mol. Biol. 1990, 215, 403-410. [CrossRef]

37. Gish, W.; States, D.J. Identification of protein coding regions by database similarity search. Nat. Genet. 1993, 3, 266-272. [CrossRef] [PubMed]

38. Finn, R.D.; Clements, J.; Eddy, S.R. HMMER web server: Interactive sequence similarity searching. Nucleic Acids Res. 2011, 39, W29-W37. [CrossRef] [PubMed]

39. Laslett, D.; Canback, B. ARAGORN, a program to detect tRNA genes and tmRNA genes in nucleotide sequences. Nucleic Acids Res. 2004, 32, 11-16. [CrossRef] [PubMed]

40. Schattner, P.; Brooks, A.N.; Lowe, T.M. The tRNAscan-SE, snoscan and snoGPS web servers for the detection of tRNAs and snoRNAs. Nucleic Acids Res. 2005, 33, W686-W689. [CrossRef] [PubMed]

41. Gautheret, D.; Lambert, A. Direct RNA motif definition and identification from multiple sequence alignments using secondary structure profiles. J. Mol. Biol. 2001, 313, 1003-1011. [CrossRef] [PubMed]

42. Lavigne, R.; Sun, W.D.; Volckaert, G. STORM towards protein function: Systematic tailored ORF-data retrieval and management. Appl. Bioinform. 2003, 2, 177-179.

43. Bailey, T.L.; Boden, M.; Buske, F.A.; Frith, M.; Grant, C.E.; Clementi, L.; Ren, J.; Li, W.W.; Noble, W.S. MEME SUITE: Tools for motif discovery and searching. Nucleic Acids Res. 2009, 37, W202-W208. [CrossRef] [PubMed]

44. Kumar, S.; Stecher, G.; Tamura, K. MEGA7: Molecular evolutionary genetics analysis version 7.0 for Bigger Datasets. Mol. Biol. Evol. 2016, 33, 1870-1874. [CrossRef] [PubMed]

45. Jones, D.T.; Taylor, W.R.; Thornton, J.M. The rapid generation of mutation data matrices from protein sequences. Comput. Appl. Biosci. 1992, 8, 275-282. [CrossRef] [PubMed]

46. Sullivan, M.J.; Petty, N.K.; Beatson, S.A. Easyfig: A genome comparison visualizer. Bioinformatics 2011, 27, 1009-1010. [CrossRef] [PubMed]

47. Krzywinski, M.; Schein, J.; Birol, I.; Connors, J.; Gascoyne, R.; Horsman, D.; Jones, S.J.; Marra, M.A. Circos: An information aesthetic for comparative genomics. Genome Res. 2009, 19, 1639-1645. [CrossRef] [PubMed]

48. Wagner, P.L.; Waldor, M.K. Bacteriophages in bacterial pathogenesis. In The Bacteriophages; Calendar, R., Abedon, S., Eds.; Oxford University Press: New York, NY, USA, 2007; ISBN 0-19-514850-9.

49. Blaisdell, B.E.; Campbell, A.M.; Karlin, S. Similarities and dissimilarities of phage genomes. Proc. Natl. Acad. Sci. USA 1996, 93, 5854-5859. [CrossRef] [PubMed]

50. Goudie, A.D.; Lynch, K.H.; Seed, K.D.; Stothard, P.; Shrivastava, S.; Wishart, D.S.; Dennis, J.J. Genomic sequence and activity of KS10, a transposable phage of the Burkholderia cepacia complex. BMC Genom. 2008, 9, 615. [CrossRef] [PubMed]

51. Summer, E.J.; Gonzalez, C.F.; Carlisle, T.; Mebane, L.M.; Cass, A.M.; Savva, C.G.; LiPuma, J.; Young, R. Burkholderia cenocepacia phage BcepMu and a family of Mu-like phages encoding potential pathogenesis factors. J. Mol. Biol. 2004, 340, 49-65. [CrossRef] [PubMed]

52. Dortet, L.; Girlich, D.; Virlouvet, A.-L.; Poirel, L.; Nordmann, P.; Iorga, B.I.; Naas, T. Characterization of BRPMBL, the bleomycin resistance protein associated with the carbapenemase NDM. Antimicrob. Agents Chemother. 2017, 61, e02413-16. [CrossRef] [PubMed] 
53. Thompson, M.K.; Keithly, M.E.; Sulikowski, G.A.; Armstrong, R.N. Diversity in fosfomycin resistance proteins. Perspect. Sci. 2015, 4, 17-23. [CrossRef]

54. Reddy, V.S.; Shlykov, M.A.; Castillo, R.; Sun, E.I.; Saier, M.H., Jr. The major facilitator superfamily (MFS) revisited. FEBS J. 2012, 279, 2022-2035. [CrossRef] [PubMed]

55. Kumar, S.; Mukherjee, M.M.; Varela, M.F. Modulation of bacterial multidrug resistance efflux pumps of the major facilitator superfamily. Int. J. Bacteriol. 2013, 2013, 204141. [CrossRef] [PubMed]

56. Makarova, K.S.; Grishin, N.V.; Koonin, E.V. The HicAB cassette, a putative novel, RNA-targeting toxin-antitoxin system in archaea and bacteria. Bioinformatics 2006, 22, 2581-2584. [CrossRef] [PubMed]

57. Mojica, F.J.M.; Díez-Villaseñor, C.; García-Martínez, J.; Almendros, C. Short motif sequences determine the targets of the prokaryotic CRISPR defence system. Microbiology 2009, 155, 733-740. [CrossRef] [PubMed]

58. Zegans, M.E.; Wagner, J.C.; Cady, K.C.; Murphy, D.M.; Hammond, J.H.; O’Toole, G.A. Interaction between bacteriophage DMS3 and host CRISPR region inhibits group behaviors of Pseudomonas aeruginosa. J. Bacteriol. 2009, 191, 210-219. [CrossRef] [PubMed]

59. Goldfarb, T.; Sberro, H.; Weinstock, E.; Cohen, O.; Doron, S.; Charpak-Amikam, Y.; Afik, S.; Ofir, G.; Sorek, R. BREX is a novel phage resistance system widespread in microbial genomes. EMBO J. 2015, 34, 169-183. [CrossRef] [PubMed]

60. Grissa, I.; Vergnaud, G.; Pourcel, C. CRISPRFinder: A web tool to identify clustered regularly interspaced short palindromic repeats. Nucleic Acids Res. 2007, 35, W52-W57. [CrossRef] [PubMed]

61. Tamura, K.; Nei, M. Estimation of the number of nucleotide substitutions in the control region of mitochondrial DNA in humans and chimpanzees. Mol. Biol. Evol. 1993, 10, 512-526. [CrossRef] [PubMed]

62. Ohnishi, M.; Kurokawa, K.; Hayashi, T. Diversification of Escherichia coli genomes: Are bacteriophages the major contributors? Trends Microbiol. 2001, 9, 481-485. [CrossRef]

63. Beres, S.B.; Sylva, G.L.; Barbian, K.D.; Lei, B.; Hoff, J.S.; Mammarella, N.D.; Liu, M.-Y.; Smoot, J.C.; Porcella, S.F.; Parkins, L.D.; et al. Genome sequence of a serotype M3 strain of group A Streptococcus: Phage-encoded toxins, the high-virulence phenotype, and clone emergence. Proc. Natl. Acad. Sci. USA 2002, 99, 10078-10083. [CrossRef] [PubMed]

64. Bodilis, J.; Denet, E.; Brothier, E.; Graindorge, A.; Favre-Bonté, S.; Nazaret, S. Comparative genomics of environmental and clinical Burkholderia cenocepacia strains closely related to the highly transmissible epidemic ET12 lineage. Front. Microbiol. 2018, 9, 383. [CrossRef] [PubMed]

65. Ronning, C.M.; Losada, L.; Brinkac, L.; Inman, J.; Ulrich, R.L.; Schell, M.; Nierman, W.C.; Deshazer, D. Genetic and phenotypic diversity in Burkholderia: Contributions by prophage and phage-like elements. BMC Microbiol. 2010, 10, 202. [CrossRef] [PubMed]

66. DeShazer, D. Genomic diversity of Burkholderia pseudomallei clinical isolates: Subtractive hybridization reveals a Burkholderia mallei-specific prophage in B. pseudomallei 1026b. J. Bacteriol. 2004, 186, 3938-3950. [CrossRef] [PubMed]

67. Yang, J.; Xu, B.; Gao, Z.; Zhou, K.; Liu, P.; Dong, Y.; Zhang, J.; Liu, Q. HicAB toxin-antitoxin complex from Escherichia coli: Expression and crystallization. Acta Crystallogr. Sect. F Struct. Biol. Commun. 2017, 73, 505-510. [CrossRef] [PubMed]

68. Butt, A.; Müller, C.; Harmer, N.; Titball, R.W. Identification of type II toxin-antitoxin modules in Burkholderia pseudomallei. FEMS Microbiol. Lett. 2013, 338, 86-94. [CrossRef] [PubMed]

69. Butt, A.; Higman, V.A.; Williams, C.; Crump, M.P.; Hemsley, C.M.; Harmer, N.; Titball, R.W. The HicA toxin from Burkholderia pseudomallei has a role in persister cell formation. Biochem. J. 2014, 459, 333-344. [CrossRef] [PubMed]

70. Cooper, V.S.; Carlson, W.A.; LiPuma, J.J. Susceptibility of Caenorhabditis elegans to Burkholderia infection depends on prior diet and secreted bacterial attractants. PLoS ONE 2009, 4, e7961. [CrossRef] [PubMed] 
71. Roszniowski, B.; Latka, A.; Maciejewska, B.; Vandenheuvel, D.; Olszak, T.; Briers, Y.; Holt, G.S.; Valvano, M.A.; Lavigne, R.; Smith, D.L.; et al. The temperate Burkholderia phage AP3 of the Peduovirinae shows efficient antimicrobial activity against B. cenocepacia of the IIIA lineage. Appl. Microbiol. Biotechnol. 2017, 101, 1203-1216. [CrossRef] [PubMed]

72. Holden, M.T.G.; Titball, R.W.; Peacock, S.J.; Cerdeño-Tárraga, A.M.; Atkins, T.; Crossman, L.C.; Pitt, T.; Churcher, C.; Mungall, K.; Bentley, S.D.; et al. Genomic plasticity of the causative agent of melioidosis, Burkholderia pseudomallei. Proc. Natl. Acad. Sci. USA 2004, 101, 14240-14245. [CrossRef] [PubMed] 